\title{
Viver o Estado Terminal de um Familiar: leitura salutogénica de resultados de um estudo de
}

caso'

\section{Living the Terminal State of a Family Member: Salutogenic interpretation of the results of a case study}

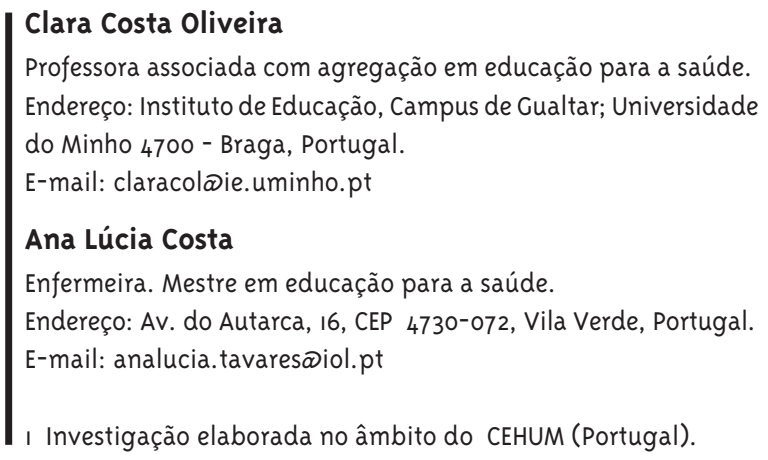

I Investigação elaborada no âmbito do CEHUM (Portugal).

Resumo

O objetivo deste artigo é interpretar dados obtidos num estudo de caso de tipo fenomenológico, que pesquisou o sofrimento de dezesseis cuidadores principais (familiares) de doentes em estado terminal, hospitalizados. Os dados desse estudo são aqui interpretados à luz do pré-paradigma salutogénico de A. Antonovsky, que promove a saúde, e não a doença, cumprindo finalidades proclamadas pela OMS, nomeadamente em Ottawa. A metodologia utilizada foi qualitativa, com recurso a interpretação hermenêutica, em conjugação com análise de conteúdo (baseada nas categorias mais importantes da conceptualização salutogénica). Os resultados obtidos revelam que todos os familiares identificaram e utilizaram vários Recursos Gerais de Resistência (GRR), passíveis de serem compreendidos à luz das três metacategorias: "compreensibilidade", "gerenciamento" e "significação". Verificou-se também que a utilização/criação dos GRR tem implícita a existência de sentidos de coerência fortes, por parte dos entrevistados, tal como enunciado por Antonovsky. Os resultados possibilitam compreender que existem áreas de formação de profissionais de saúde que podem ser estimuladas em situações similares à estudada. Algumas dessas áreas são a comunicação e a gestão emocional. Os resultados apontam também para a necessidade de investimento em ações de educação para a saúde que promovam o empoderamento psicológico e comunitário dos indivíduos e dos grupos, em geral.

Palavras-chave: Sofrimento; Familiar; Estado terminal. 


\section{Abstract}

The aim of this paper is to interpret data obtained in a phenomenological case study that researched the suffering of sixteen main caregivers (family members) of terminally ill hospitalized patients. The data of that study are interpreted here in light of A. Antonovsky's salutogenic pre-paradigm, which promotes health, not disease, fulfilling the objectives proclaimed by WHO, particularly in Ottawa. The methodology that was used was qualitative with hermeneutic interpretation, combined with content analysis (based on the most important categories of the salutogenic conceptualization). The results show that all the family members identified and utilized various General Resistance Resources (GRR), which can be understood in light of three metacategories: 'comprehensibility', 'manageability' and 'meaningfulness'. It was also found that the use/creation of the GRR implies the existence of strong senses of coherence on the part of the respondents, as stated by Antonovsky. The results allow us to understand that there are areas of health professionals' training that can be stimulated in situations similar to the studied one, such as communication and emotional management, among others. They also point to the need for investment in health education activities, promoting psychological and community empowerment.

Keywords: Suffering; Family Member; Terminal State.
A salutogenic orientation, which does not in the least disregard the fact that a person [...] has been given 2 weeks to live as a 'terminal cancer patient' [...] must relate to all aspects of the person. (Antonovsky, 1996, p. 14).

\section{Introdução}

Os resultados aqui interpretados, numa perspectiva salutogénica (Antonovsky), provêm de um estudo de caso realizado no âmbito de uma dissertação em Educação para a Saúde, na Universidade do Minho (Portugal), da qual foi orientadora científica a primeira autora deste artigo. A segunda autora, a pesquisadora dessa dissertação, estudou o sofrimento de familiares de doentes terminais hospitalizados, em $2007^{2}$. Procedeu a uma pesquisa qualitativa de estudo de caso, de âmbito fenomenológico, tendo recorrido ao método hermenêutico, em conjugação com análise de conteúdo de dezasseis entrevistas semi-estruturadas.

No final daquele seu trabalho, a autora enunciou, ainda que rapidamente, algumas pistas de abordagem dos dados obtidos, tendo em conta o modelo salutogénico. É propósito deste artigo aprofundar essa interpretação salutogénica, que não foi anteriormente explorada no estudo mencionado, mas apenas aflorado nas suas conclusões. 0 recurso, neste artigo, aos dados do referido estudo enquadram-se pois em propósito investigativo.

Possuir capacidade de integrar o sofrimento no sentido, coerente, que a nossa vida possui, não acontece a todos. Acontece a alguns, e conforme o contexto. Quando esse contexto inclui um familiar (de quem somos cuidadores principais) a quem o prognóstico de sobrevivência atribuído é seis meses, o contexto afigura-se adverso para a construção/ manutenção de sentido interno na nossa vida. E, no entanto, tal é possível de ocorrer, como veremos.

\section{0 pré-paradigma salutogénico}

Um paradigma caracteriza-se, segundo Kuhn (1962) por se diferenciar radicalmente daquele que o prece-

\footnotetext{
2 A dissertação foi defendida publicamente em 2008, na Universidade do Minho (Portugal), e o seu título é: No fim da linha. O sofrimento da família do doente em fase terminal: implicações na Educação para a Saúde: COSTA, A. L. A. No fim da linha. 0 sofrimento da família do doente em fase terminal hospitalizado: implicações na Educação para a Saúde. Braga, 20o8. Tese (Mestrado em Educação para a Saúde) - Instituto de Educação e Psicologia, Universidade do Minho, Braga, Portugal, 2008.
} 
deu; é uma metateoria organizada e estruturada que se impõe a todas as formas de explicação científica de uma determinada época. "Men whose research is based on shared paradigms are committed to the same rules and standards for scientific practice" (Kuhn, p. 11, 1962).

Assim, podemos falar do paradigma ptolemaicoeuclidiano-aristotélico que, não sendo científico - propriamente dito -, constituía uma epistemê profundamente articulada e lógica. Sucedeu-lhe o paradigma mecanicista, que inicia a scientia, rigorosamente falando.

Um paradigma assenta em pressupostos, crenças de tipo histórico-cultural, que determinam o tipo de questões que se podem colocar, os seus jogos de linguagem (Wittgenstein, 1995). A pretensa objetividade científica joga-se dentro deste quadro, seja qual for a teoria científica que escolhamos. Obviamente que os métodos a adotar no paradigma constituem-se também como regras do jogo de linguagem embasado pelas crenças mencionadas. Uma das causas de mudança de paradigma é a mudança de crenças; outra, a acumulação de dados empíricos não explicáveis pelo paradigma em vigor: "New paradigms arise with destructive changes in beliefs about nature" (Kuhn, p. 98, 1962).

Jonas (2005), entre outros, refere que essa foi uma das razões que levou a que o mecanicismo se tornasse o paradigma da ciência moderna. Com efeito, com a dessacralização progressiva do mundo, com a retirada da anima do mundo físico, abria-se a porta para um paradigma já não interessado em responder à finalidade (para quê?) do devir, e do ser, do mundo. Este passa a ser explicado pelo "como", por já não ter anima (alma) que o oriente para lado algum. Durante alguns séculos, no mundo humano, permaneceu ainda o resquício da finalidade do mundo físico, mas no final do século XIX o mundo humano tinha também aderido ao paradigma mecanicista. A única resistência ocorreu na (alguma) Filosofia.

A pesquisa sobre a saúde humana esteve desde sempre inserida, obviamente, no paradigma das épocas históricas. Assim, a medicina ocidental, que se desenvolveu sobretudo a partir do séc. XIX, centrou- se no método causal de tipo eficiente, ou formal (utilizando aqui, provocatoriamente, a linguagem aristotélica), que trouxe imensos benefícios para a humanidade, nomeadamente ao nível da medicação. Uma medicina evidence-based, como hoje é reclamada, assenta explicitamente no método experimentaldedutivo que no século XIX estava constituído, e reconhecido, como próprio da ciência normal. Um dos principais instrumentos de difusão e imposição da ciência normal é o sistema educativo, e tal aconteceu também nos saberes ligados à saúde humana, nomeadamente na medicina; a pesquisa desta área (bem como noutras) é "a strenuous and devoted attempt to force nature into the conceptual boxes supplied by professional education" (Kuhn, p. 5, 1962).

No mesmo século em que os saberes humanos se inseriam no paradigma mecanicista, e no qual a medicina se assumia como ciência, sobretudo de raiz bioquímica, começaram a surgir posicionamentos pré-paradigmáticos (Kuhn, p. 18, 1962), quer na física, quer na matemática. Eles irromperam com imensa força já no século XX, nomeadamente com as concepções da mecânica quântica e das geometrias não euclidianas, bem como com as controversas, mas irrefutáveis, demonstrações, na lógica pura, de Godel.

No nosso entender, a medicina foi pouco afetada por esta dimensão pré-paradigmática até ao pensamento de Aaron Antonovsky. Por imposição da normatividade da ciência moderna, a medicina transformara-se no mundo da explicação da patogenia, e da sua prevenção, sobretudo secundária. A prevenção primária, e a terciária, ocorreram sobretudo a partir da segunda metade do século passado.

Com Antonovsky, porém, surgiu o conceito de salutogenia, que colocou em causa muitas das crenças da medicina ocidental, sobretudo por se focalizar na dimensão de produtividade de sáude (enquanto bem-estar, percebido como expressão das várias dimensões da vida de uma pessoa). Esse autor não negava a doença, nem a sua importância para a área da saúde humana. Ele considerava, no entanto, que ela não se opõe à saúde; ambas se articulam num continuum, que é a própria vida ${ }^{3}$.

3 É bem conhecida a metáfora de Antonovsky, na qual a vida é considerada um rio no qual todos nós estamos. Ela proporciona uma visão dinâmica da existência humana, na qual tanto podemos estar a boiar descontraidamente, como numa zona de precipícios. Mas está-se sempre dentro do rio. Há pois uma rejeição do dualismo doença/saúde. Cfr. Antonovsky, 1988. Eriksson e Lindström figuraram esta metáfora: cfr. Eriksson e Lindström, 2008. 
Pesquisar a salutogenia significa focalizarmos a nossa atenção naquilo que resiste aos fatores estressantes (stressors) da vida humana, contrapondo-se esta pesquisa àquela que procura os fatores predisponentes para o surgimento de patologias.

Assim, por exemplo, uma pesquisa salutogénica sobre o consumo de tabaco deveria focalizar--se em pessoas que, tendo estado continuamente sujeitas a ambientes de consumo desta substância desde tenra idade, decidiram no entanto não a consumir. Outra hipótese seria estudar por que pessoas que fumam tabaco desde crianças se mantêm sem problemas patogénicos associados a esse consumo, após 70 anos de vida. Esses tipos de estudos procuram, pois, inquirir sobre como, em que circunstâncias, se produz saúde.

Aquilo que se tem verificado é que este tipo de abordagem implica uma pesquisa de cariz holista, onde a causalidade eficiente tem que ser enquadrada em uma causalidade múltipla (vários fatores que ocorrem a simultaneo são necessários para explicar a salutogenia, dado o seu caráter complexo), bem como, muitas vezes, em uma causalidade retroativa, dado que a dimensão do equilíbrio homeostático é importante para a compreensão de fenómenos de salutogenia. Uma perspectiva teleológica é outra das regras epistemológicas que esta perspectiva tem implícita, pois a salutogenia se direciona para o bem-estar global da pessoa (e não só do organismo). Intrincada com essa questão, verifica-se - na concepção salutogénica- um posicionamento não dualista (corpo/mente), contrariamente àquele que ocorre no paradigma mecanicista.

Muito se tem escrito sobre o pensamento de Antonovsky, a ele recorrendo para enquadrar teorias e modelos. Ainda em vida, ele mostrou-se céptico em relação a este tipo de abordagem do seu pensamento, nomeadamente à eventual ligação da sua abordagem com os "fatores de risco", "estilos de vida", "psicosomatização”. A capacidade de apropriação daquilo que perturba o seu poder, caracteriza também um paradigma:

In the 1930s it was revolutionary to suggest that something in the mind could lead to somatic diseases. Today, I submit (though many would disagree), we are held back by the concept, because it implies that some diseases are psychosomatic and others are not. It perpetuates dualistic thinking and prevents us from seeing that all human distress is always that of an integrated organism, always has a psychic (and a social, I might add) and a somatic aspect (Antonovsky, p. 11, 1996).

Os autores que mais têm difundido o pensamento de Antonovsky são Eriksson e Lindström, que, na linhagem do próprio Antonovsky, consideram que falta uma fundamentação teórica sólida nas perspectivas defendidas por Ottawa. Aqueles autores consideram que ela poderia ser fornecida pelo pensamento de Antonovsky; eles têm tido ainda um papel crucial na completude metodológica do pré-paradigma salutogénico.

In the 1980s, Antonovsky's salutogenic model of health influenced the development of health promotion (although not explicitly stated in the Ottawa Charter). The underlying theories of health promotion research were discussed in a seminar held at the WHO Regional Office in Copenhagen in 1992. Antonovsky attended this workshop and presented his salutogenic model as one direction for health promotion. There was an agreement and conclusion that the focus henceforth should be on health rather than on disease. This was a fundamental shift from the old and previous theoretical perspectives that largely stemmed from the biomedical model of disease (Eriksson e Lindström, p. 191, 2008).

\section{Conceitos Base da Teoria da Salutogenisis em A. Antonovsky}

Aaron Antonovsky (1923-1994) desenvolveu o conceito salutogenisis a partir de uma pesquisa que realizou com dois grupos de mulheres sobre a percepção de felicidade nas suas vidas. Um desses grupos era constituído por mulheres que tinham estado em campos de concentração na II Guerra Mundial. Os resultados do estudo foram surpreendentes: a maior parte delas considerava-se mais feliz (e possuía uma menor incidência de doenças) que as mulheres do outro grupo!

Antonovsky decidiu saber porquê, dedicando a sua vida a esta questão: como é que (algumas) pessoas sujeitas a situações extraordinariamente adversas na vida conseguem se sentir felizes e vivem 
com menor incidência de patologias?

A hipótese a considerar era que a saúde de uma pessoa dependia muito mais de si própria do que dos fatores externos, aos quais estaria submetida. Colocou a hipótese de haver formas de produzir saúde, mesmo em situações adversas e plenas de estresse (como passar fome, estar sujeito a tortura, ver os seres que ama serem mortos, etc.).

A investigação deste autor leva à conclusão que ter saúde é muito mais do que não ser portador de patogenias; induz, aliás, que a patogenia é muitas vezes uma consequência de quem não consegue produzir saúde em sua vida.

A produção de saúde ocorre quando as pessoas encontram sentido para o sofrimento ao qual vão estando sujeitas ao longo da vida, conseguindo descobrir soluções para problemas com os quais se deparam continuamente.

O modo mais usual de criar soluções é utilizando corretamente recursos gerais de resistência (GRR-Generalised Resistance Resources), de vários tipos ${ }^{4}$, agrupados por Antonovsky em três grandes categorias: compreensibilidade (comprehensibility), gerenciamento (manageability) e significação (meaningfulness).

O primeiro remete para a explicação racional da ocorrência de um fenómeno, por muito desconfortável que ele seja. Utiliza-se uma causalidade formal, ou eficiente, que nos possibilita tornar compreensível (ainda que permaneça desagradável) determinada experiência, com a qual nos confrontamos.

Comprehensibility [...] refers to the extent to which one perceives the stimuli that confront one, deriving from the internal and external environments, as making cognitive sense [...]. The person high on the sense of comprehensibility expects that stimuli he or she will encounter, then they do come as surprises, that they will be orderable or explicable. [...] (Antonovsky, 1988, p. 17).

0 gerenciamento refere-se à identificação e à utilização dos recursos físicos (pessoais e comunitários) aos quais podemos recorrer para melhor suportar ocorrências difíceis. São esses recursos que possibilitam alguma (ou muita) esperança face a situações de sofrimento.

Manageability is the extent to one perceives that resources are at one's disposal which are adequate to meet the demands posed by the stimuli that bombard one. [...] To the extent one has a high sense of manageability one will not feel victimized by events or feel that life treats one unfairly. Outward things do happen in life, but when they occur, one will be able to cope and not to grieve endlessly. [...] (Antonovsky, 1988, p. 17-18).

0 recurso de significação refere-se à atribuição de sentido às experiências vividas, quer às percebidas como boas, quer às percebidas como más. Atribuir significação implica aceitar que a vida não se opõe ao sofrimento, mas este dela é parte intrínseca. Aceitá-lo e encontrar estratégias de não nos perdermos de nós próprios nos momentos menos felizes, constitui um dos resultados do recurso da significação.

The meaningfulness component [...] refers to the extent to which one feels that life makes sense emotionally, that at least some of the problems and demands posed by living are worth investing energy in, are worthy of commitment and engagement, are challenges that are „welcome rather than burdens that one would much rather do without. [...] When unhappy experiences are imposed [...] he or she will willingly take up the challenge, will be determined to seek meaning in it, and will do his or her best to overcome it with dignity (Antonovsky, 1988, p. 19).

No entanto, segundo Antonovsky, estas capacidades de atribuição de significação, de utilização dos recursos disponíveis, e de compreensão da especificidade e dos contornos do sofrimento que estamos a viver, só se obtêm quando possuímos sentido interno de coerência (SOC), ou seja, quando tivermos desenvolvido, no percurso da nossa existência, uma profunda e sólida noção de identidade que resista ao efeito desestruturador que o sofrimento sempre acarreta ${ }^{5}$. O SOC é passível de ser reforçado,

\footnotetext{
4 Veja-se nota 9 deste artigo.

5 «Suffering is a state of severe distress associated with events that threaten the integrity (intactness) of a person. [...] Suffering requires consciousness of the self, involves the emotions, has effects on the person's social relationships, and has an impact on the body CASSELL, E. The nature of suffering and the goals of medicine. Oxford: Oxford University Press, p. 32 e 224, 2004.
} 
flexibilizado, desenvolvido, desde que nascemos até morrermos, sendo que usualmente aumenta no decorrer de uma vida mais longa.

Os três tipos de GRR mencionados foram encontrados em todas as pessoas estudadas por Antonovsky, evidenciando, também, forte sentido de coerência; muito embora estando relacionados entre si, algumas pessoas são melhores na utilização e construção de uns GRR, em detrimento de outros. Tal se relaciona com o conteúdo do sentido de coerência existencial das pessoas em causa.

Uma das questões que Antonovsky nos legou foi indagar sobre como se constitui o SOC; trata-se de uma questão de tipo salutogénico, por excelência. Não o sabemos, mas tudo indica que a vertente pessoal é muito maior que qualquer influência do meio na sua constituição. Neste âmbito, construiu-se uma escala de aferição do SOC de cada pessoa, que já foi validada em várias culturas. Os interessados na escala podem encontrá-la nas obras de Bengt Lindström e Monica Eriksson (Eriksson e Lindström, 2005).

Outros autores têm vindo a articular o pensamento de Antonovsky, nomeadamente no que respeita à constituição do SOC, com as concepções epistemológicas dos chilenos H. Maturana e F. Varela, autores da teoria da autopoiesis (Arond-Thomas, 200o). Tal parece-nos um caminho a explorar no futuro, bem como a articulação do SOC com teorias de outros autores do movimento da Auto-organização, onde se inclui, aliás, a teoria da autopoiesis ${ }^{6}$. Propomo-nos, a breve prazo, articular a constituição, e desenvolvimento, ontogenéticos do SOC com o conceito "padrão” auto-organizativo, de Gregory Bateson.

\section{Desenho do Estudo e Resultados Obtidos}

Como mencionado, os resultados sobre os quais nos debruçaremos tiveram como população alvo cuidadores principais (quatorze mulheres e dois homens) de dezasseis doentes hospitalizados, diagnosticados com doença oncológica e com um prognóstico de vida não superior a seis meses. As entrevistas, semiabertas, foram orientadas por um guião, tendo em conta a bibliografia da especialidade, e entrevistas feitas a especialistas. De seguida foi aplicado um pré-teste do guião da entrevista a quatro cuidadores principais, do qual resultaram algumas modificações, incluídas na versão final do guião.

O tratamento das entrevistas utilizou categorias definidas a partir da recolha exaustiva da bibliografia sobre sofrimento e sofrimento de cuidadores.

O número pequeno da amostra deve ser compreendido dado o prazo temporal que houve para a realização (um ano) deste estudo, que seguiu os trâmites éticos e deontológicos a ele adequados. Assim, foi solicitada (e obtida) autorização à Comissão de Ética da unidade hospitalar onde decorreram as entrevistas; a população inquirida foi informada conveniente, e adequadamente sobre os objetivos do estudo, tendo dado o seu consentimento, por escrito. Manteve-se o anonimato em todos os dados recolhidos.

Os resultados obtidos foram arrumados em vários quadros ${ }^{7}$, tendo por referência as categorias daquela pesquisa, a saber:

Quadro I - Descrição das necessidades da família do doente em fase terminal hospitalizado: necessidade de informação; de participação nos cuidados prestados ao doente; de aprendizagem (necessidades no que se refere ao doente). No que respeita às necessidades dos cuidadores principais, ressaltaram as de tipo físico, de tipo psíquico/emocional, de tipo relacional/social e de tipo espiritual.

Foram ainda identificadas necessidades relacionadas com outros elementos da família, que não o cuidador principal (eg.: estar com os filhos, protegendo-os, bem como familiares mais frágeis, da situação de sofrimento; gerir conflitos na família; conseguir dar andamento a situações pendentes, em termos financeiros).

Quadro II - Fatores incrementadores do sofrimento em contexto hospitalar: foram identificados onze fatores, que aqui se apresentam em três grupos: 1- presenciar o sofrimento e a dor dos doentes; 2 - as-

6 Cf. OLIVEIRA, C. C. A educação como processo auto-organizativo - fundamentos teóricos para uma educação permanente e comunitária. Lisboa: Instituto Piaget, 1999 e OLIVEIRA, C. C. Auto-organização, educação e saúde. Coimbra: Ariadne, 2004.

7 Apresentam-se, de seguida, sucintamente, o que continham esses quadros. Para uma leitura mais pormenorizada, deverá consultar-se a mencionada dissertação, nomeadamente da p. 296 à p. 381. 
sistir aos procedimentos médicos e de enfermagem (adequados, distanásicos, negligenciados) para alívio da dor e/ou manutenção da vida dos doentes; 3 - questões ligadas à dimensão relacional/comportamental dos doentes (eg: na expressão -histriónica ou omissa - de afetos entre doentes e familiares).

Quadro III - Refere-se aos direitos familiares, identificando-os: a) direitos dos cuidadores principais; b) direitos dos familiares em geral, desde que considerados cuidadores dos doentes; c) direitos comunitários relacionados com este tipo de situação.

Quadro IV - Descreve o papel dos profissionais de saúde, na perspectiva dos entrevistados, na aceitação/integração do sofrimento. São identificadas nove atitudes, todas de dimensão relacional, nos profissionais de saúde, quer para com o doente, quer para com a família.

Quadro V - Classifica as manifestações do sofrimento. Os cuidadores principais entrevistados identificaram vários tipos de sofrimento: físico, psicológico/emocional, social e espiritual.

Quadro VI - Verifica se os entrevistados diferenciam dor de sofrimento e sofrimento de dor total ${ }^{8}$. Os resultados descritos neste quadro são muito interessantes, pois aqueles cuidadores conseguiram identificar situações de dor sem sofrimento e de sofrimento sem dor. Em algumas situações o sofrimento aparece identificado com dor total, mas nem sempre é entendido como tal.

Quadro VII - Trata das causas atribuídas ao sofrimento. São enunciadas causas : de índole transcendental e comportamental, de caráter naturalizado e de fracasso da medicina atual.

Quadro VIII - Expõe os recursos utilizados no alívio do sofrimento, tendo sido classificados em recursos pessoais e em recursos externos à própria pessoa.
Quadro IX - Refere-se às aprendizagens que os inquiridos consideram ter obtido com o sofrimento a que estiveram sujeitos.

\section{Salutogenia e Sofrimento}

Tendo por base os resultados anteriormente descritos, procederemos agora à sua interpretação de um ponto de vista salutogénico.

Assim, os resultados obtidos apontam claramente para a capacidade dos entrevistados em utilizarem recursos gerais de resistência (GRR); o sofrimento acentua-se quando existem (no entender dos entrevistados) essa falta de recursos, ou o não assumir dessa falta ${ }^{9}$. Antonovsky apelidou esta situação de "deficiência de recursos de resistência" (Generalized resistance deficits - GRD: Antonovsky, 1985).

Começando pelos recursos ambientais e naturais, eles estão assinalados nos quadros VII, VIII e II. Alguns dos entrevistados utilizam a natureza como fator explicativo do sofrimento que estão a suportar, mencionando a inevitabilidade biológica da morte e a hereditariedade como causa da doença do familiar, por exemplo. Para outros, o convívio com os animais e a imersão na natureza (face ao mar, no silêncio do campo/montanha) revela-se um recurso forte de apaziguamento do sofrimento.

De salientar que são também indicados como incrementadores do sofrimento (quadro II) a falta de recursos ambientais no hospital (como a ausência de privacidade, e o excesso de ruído), bem como a recusa em aceitar a falta de recurso natural orgânico do doente, recorrendo-se então à futilidade terapêutica.

No que se refere aos recursos físicos e bioquímicos, eles são mencionados sobretudo nos quadros I, VII, VIII e II. Das entrevistas, ressaltam a necessidade de os cuidadores assegurarem um sono repa-

8 Tenha-se em conta a definição de sofrimento, apresentada na nota 5 .

9 A classificação de recursos a seguir apoia-se em Antonovsky, 1985, sendo que o autor apresenta outros, para além dos aqui mencionados. É praticamente infinita a capacidade de criar GRR; referem-se de seguida os mais usuais, que brevemente caracterizamos: 1- Ambientais e naturais: vivendo em ambientes pouco poluídos, consumindo água potável, contatando amiúde com a natureza, etc.; 2 - Físicos e bioquímicos: exercitando o corpo e a mente, alimentando-se de modo a assegurar nutrientes básicos, utilizando a panóplia de substâncias químicas ao dispor da humanidade, etc.; 3 - Emocionais: exprimindo emoções em contextos adequados; gerindo emoções; sendo receptivo às emoções dos outros, etc.; 4 - Interpessoais: desenvolvendo e mantendo uma rede de amigos; tratando e sendo tratado como igual em contextos profissionais, etc; 5 - Socioculturais: apreciando arte, produzindo e consumindo cultura, tendo momentos de lazer e de ócio, praticando regularmente rituais de espiritualidade ou de religião (como meditação, oração). 
rador e uma alimentação equilibrada, bem como a importância dos recursos terapêuticos, como a radio e a quimioterapia.

A ligação do sofrimento à dor pode ser desfeita, no entender de alguns entrevistados, pelo recurso a substâncias químicas e bioquímicas. A causa da doença surge mencionada, por alguns, como tendo sido a má utilização de recursos físicos, maus hábitos alimentares (consumo de álcool, por exemplo), a falta de atividade física, o uso de substâncias tóxicas (tabaco, por exemplo) etc. Outros apontam a insuficiência química no tratamento administrado em determinadas fase da doença do familiar como sendo causa da doença, ou seja, consideram não ter havido uma utilização adequada dos recursos químicos existentes na medicina contemporânea. Alguns referenciam a falta deste tipo de recursos, ao nível médico, para o tratamento de determinadas doenças. Os procedimentos distanásicos, com exacerbante uso de substâncias químicas e procedimentos tecnológicos, são considerados como um abuso dos recursos físicos e bioquímicos.

Nas entrevistas, encontra-se também mencionada a utilização de recursos emocionais, nomeadamente nos quadros I, II, IV, V, VI, VIII e IX. Salientamos que este é, provavelmente, o GRR mais mencionado nas entrevistas, quer no seu aspecto positivo, quer no negativo (quando ele não consegue ser ativado e/ou construído). Os familiares entrevistados tinham perfeita consciência que a sobrevivência à situação de sofrimento na qual se encontravam implicava uma gestão emocional complexa, pois mencionam explicitamente a necessidade de se dar atenção aos filhos e de proteger os familiares considerados mais frágeis face à situação em que se encontravam. Foi ainda referido que a gestão de conflitos familiares se mostrava muito importante naquelas circunstâncias; relevante foi também a existência de um relacionamento pacificante com o doente, bem como a capacidade de reconhecimento cognitivo do familiar, por parte do doente.

A maior parte destas pessoas soube identificar a gestão dos seus sentimentos/emoções como fundamentais na resiliência à situação vivencial em que se encontrava. As emoções enunciadas são as que os especialistas (Marie de Hennezel, Neimeyer, Kubler-Ross, por exemplo) consideram ocorrer mais usualmente nestas situações: tristeza, medo, revolta, sentimento de impotência, impaciência/irritabilidade e culpa. Muitos deles souberam distinguir dor de sofrimento, e quase todos consideraram que um dos recursos de resistência ao sofrimento, nessas situações, era a gestão emotiva adequada por parte dos profissionais de saúde. Foram identificadas as seguintes atitudes, na diminuição do sofrimento desses familiares: os profissionais de saúde escutarem os doentes; mostrarem preocupação e disponibilidade para com o doente/família; valorizarem a dor e o sofrimento do doente/família; serem delicados (sorrindo, por exemplo) com o doente/família.

Recursos pessoais positivos face ao sofrimento, naquele contexto, foram: o choro, a solidão e a capacidade de manter a esperança face à vida, em geral. Vários entrevistados referiram que a utilização destes recursos de índole emocional os tinha transformado em pessoas mais tolerantes aos outros.

Em contrapartida, foram enunciados como fatores que inibem a construção de recursos de tipo emotivo: a indiferença e/ou o desprezo demonstrados por alguns profissionais de saúde no cuidado dos familiares e dos doentes, nomeadamente a incapacidade para escutar; a indiferença ao falarem demasiado alto e sobre temas não relacionados com o doente; não comparecerem junto do doente quando este tem dor. Foram também referidas, neste contexto negativo, a futilidade de determinados tratamentos ministrados ao doente em fase terminal e a transmissão da notícia do falecimento por meio de uma ligação telefónica.

Profundamente ligados ao recursos emocionais encontramos os recursos interpessoais. Os discursos inseridos no Quadro VIII indicam explicitamente a família e os amigos como recursos de resiliência ao sofrimento destes cuidadores principais. A ocupação laboral (e/ou suporte económico) é outro recurso indicado pelos entrevistados, noutros quadros, bem como a relação interpessoal atenta e compassiva por parte dos profissionais de saúde, quer para com o doente, quer para com o cuidador principal. De salientar a acusação da falta de suporte por parte da assistência social governamental que deveria ser, no entender dos entrevistados, um recurso primordial.

Antonovsky insere nos recursos socioculturais 
tanto a dimensão artística e espiritual, como a religiosa. Ainda que não concordando com essa inserção (consideramos que a dimensão espiritual, ou pelo menos a religiosa, deveriam ser diferenciadas como recurso), seguiremos a classificação do autor. A análise interpretativa tem por base dados recolhidos em quase todos os quadros anteriormente mencionados, com algumas exceções, como o II e o III.

Alguns dos cuidadores principais indicaram o estudo e a leitura, como recursos para lidar com o seu sofrimento. Mas o elemento mais reconhecido é, sem dúvida a dimensão espiritual (dar sentido à vida e à morte) e religiosa ("Deus quer junto de si aqueles que são melhores", "com o sofrimento, Deus pretende que nos aperfeiçoemos”, etc). Alguns dos entrevistados consideram que a descrença em Deus (que pode emergir do sofrimento) é um fator de desespero, quer seu, quer dos doentes. Daí valorizarem bastante a atitude dos profissionais de saúde que apelam à presença de guias espirituais, de acordo com as crenças dos doentes e seus cuidadores principais.

Os incontáveis GRR com que cada ser humano se pode deparar, e criar, foram agrupados, como vimos, por Antonovsky em três grandes metacategorias: compreensibilidade (comprehensibility), capacidade de gerir (manageability, usualmente traduzido por gerenciamento) e significação (meaningfulness).

Face aos resultados dos dados do estudo mencionado, também passamos a agrupá-los nestas três metagategorias, como segue.

Recursos de compreensibilidade enunciados pelos cuidadores principais dos doentes em estado terminal ${ }^{10}$ : a informação é claramente um recurso considerado indispensável para poder sobreviver com dignidade a este tipo de sofrimento, por estas pessoas. Mencionaram a necessidade de serem informados sobre aquilo que é uma doença terminal, sobre quais as necessidades dos doentes nesse tipo de situação, bem como sobre a evolução plausível da doença. A informação sobre as necessidades com que os cuidadores principais usualmente se deparam, surge também como um recurso, dada a dimensão preventiva face ao sofrimento.
Outro recurso de compreensibilidade mencionado foi a aprendizagem que se pode obter com o sofrimento, sendo retratado que ele possibilita, para quem consiga integrá-lo positivamente (o que não é sinónimo de alegremente) nas suas vidas, uma maior tolerância, paciência, disponibilidade perante o outro. Indicaram ainda a valorização das potencialidades das pessoas e a das alegrias que a vida nos proporciona, por mais simples que aparentemente sejam.

A distinção entre dor, dor total e sofrimento permitiu também aos entrevistados compreender melhor e aceitar a situação que se encontravam a viver. Lembremos que essa diferenciação foi manifestada nas entrevistas, ainda que nem sempre de forma clara.

Alguns recursos de gerenciamento ${ }^{11}$ sobressaíram nos discursos dos entrevistados, nomeadamente o apoio de familiares, (ao nível econômico), bem como a compreensão da situação por parte da entidade laboral (quando, por exemplo, o familiar entrevistado teve que trabalhar menos horas, de modo a cuidar do doente hospitalizado, em estado terminal), e ainda o recurso dos sistemas de assistência social nacionais.

Outro recurso assinalado como muito importante, neste contexto, foi a medicação, bem como a tecnologia, que foram utilizadas a bem do doente, e do seu cuidador principal.

Um dos recursos de resistência ao sofrimento mais aludido por essas pessoas remeteu para as atitudes e os comportamentos dos profissionais de saúde do hospital. Um desempenho cuidador e atento foi avaliado como muito positivo, não só para o doente, mas também para os familiares, nomeadamente no cumprimento dos direitos destes últimos.

Os entrevistados fizeram ainda menção a recursos de significação ${ }^{12}$, sobretudo de ordem espiritual. O seu sofrimento, e aquele de quem cuidaram, foram integrados em sentidos últimos já mencionados, como a inevitabilidade genética, a vontade de um ser superior, etc. Também a responsabilidade pela proteção daqueles que ficaram, sobretudo os mais

10 Correspondem, grosso modo, aos dados inseridos nos quadros I, IX e VI.

11 Encontram-se mais facilmente detectáveis nas declarações incluídas nos quadros I, III e VIII.

12 Especialmente identificáveis nas declarações enquadradas pelos quadros IV e VIII. 
vulneráveis, contribuiu para que o sofrimento fosse perspectivado com significação.

Esses três grandes grupos de recursos que as pessoas entrevistadas criaram/utilizaram estão interligados entre si. A sua separação decorre do âmbito observacional-investigativo, pois na vivência concreta das pessoas eles remetem uns para os outros; por exemplo: a natureza como recurso surge nos entrevistados como base da compreensão do devir que ocorre em todos os seres vivos (não há vida sem morte). Ora, essa compreensão permite a atribuição de significação ao sofrimento a que estavam a ser sujeitados. Notemos, porém, que nem todos os entrevistados mencionaram a natureza como recurso. Quem o fez, possuía capacidade de gerenciamento, ou seja, conseguiu utilizar a natureza como recurso de resistência.

Salientamos que os resultados apurados no âmbito do quadro II são-nos úteis para identificar GRD, a incapacidade de utilizar/criar recursos face a determinadas situações.

Tendo em conta a descrição feita anteriormente, devemos concentrar-nos no testemunho dessas pessoas para melhorarmos o ambiente natural, e sobretudo humano, dos hospitais, especificamente dos espaços onde estão doentes terminais internados. Os resultados revelam também, no caso estudado, alguma indiferença por parte dos profissionais de saúde face à presença dos familiares (incapacidade de escuta, por exemplo, foi algo referido).

Essas situações devem ser objeto de reflexão, pois são aquelas com as quais os entrevistados tiveram mais dificuldade em lidar, sendo consideradas situações que incrementaram o seu sofrimento.

Este tipo de estudo possibilita uma reflexão sobre a formação que estamos a proporcionar aos profissionais de saúde. Será que eles percebem que os familiares possuem recursos gerais de resistên- cia? Será que eles têm consciência da importância que possuem na criação/desenvolvimento desses recursos, quer junto dos doentes, quer junto dos familiares, nomeadamente com as suas atitudes e comportamentos? Será que eles compreendem que doentes/familiares que criam e utilizam GRR aliviam imensamente a tensão e melhora no acompanhamento dos doentes, evitando situações de burnout?

Consideramos também que se deve incrementar formação não formal para a população em geral ${ }^{13}$. A promoção da saúde não tem que ser apenas fomentada no que respeita à prevenção (primária, secundária ou terciária) de doenças. Ela pode também abranger o desenvolvimento de capacidade de empoderamento (empowerment $\mathrm{t}^{14}$ ) da população em geral, e de grupos específicos, num posicionamento salutogénico. Com efeito, o empoderamento comunitário reforça a capacidade de identificar, e utilizar recursos comunitário-sociais (GRR gerenciamento); o empoderamento psicológico tem, no entanto, que preceder o comunitário e refere-se diretamente aos GRR da compreensibilidade e da significação.

Todos somos cuidadores ao longo da nossa vida, e todos temos fortes probabilidades de virmos a ser cuidadores principais de doentes terminais e/ou doentes terminais. Desenvolver conhecimentos e competências que nos possibilitem a criação/utilização de recursos nesses momentos difíceis é de uma enorme importância. Toda a sociedade possui responsabilidade neste papel, nomeadamente as universidades que devem se abrir à comunidade em geral, patrocinando este tipo de evento de formação não formal.

A potencialização das pessoas é especialmente importante pelo fato (estudado por Antonovsky) de as pessoas só utilizarem recursos que estejam à sua disponibilidade se tiverem anteriormente desen-

13 Decorrente deste posicionamento, foram organizados vários workshops (e um curso breve), abertos à população em geral, no Instituto de Educação da Universidade do Minho, em Portugal: "Formação de cuidadores de saúde pela literatura"; "questões éticas na formação de cuidadores de saúde", "as dúvidas e as dores de quem vê sofrer”, "educação para o sofrimento: a saúde do luto". 0 tema do curso foi "educação para o sofrimento e para a morte”, organizados por Clara Costa Oliveira.

140 empoderamento é um processo complexo, implicando informação, bem como tomada de consciência, face à situação atual na qual os indivíduos/grupos se encontram, pela construção de um projeto de mudança em função de necessidades e objetivos concretos. É-lhe também inerente a ação interventiva e autónoma. A implementação de práticas que promovam o empowerment exige abordagens educativas que rompam com atitudes e comportamentos centrados no poder sobre os outros. Eles deverão ser substituídos por métodos que valorizem a reflexão e a crítica, estimulando os indivíduos, ou grupos, a tornarem-se cidadãos que tomam decisões livres, conscientes e informadas, em relação ao seu processo de saúde/doença. 
volvido sentido interno de coerência. Este estudo ajuda a confirmar isso pois, por exemplo, a crença em Deus é para alguns um GRR, mas para outros tornou-se, neste contexto, um fator de maior sofrimento. Porquê? Provavelmente porque a crença em Deus foi-se construindo, ao longo da vida de alguns, incorporando nela o sofrimento, e noutros tal não aconteceu (pelo menos o sofrimento pessoal). Assim, nesses tipos de situações a crença em Deus surge como um fator de equilíbrio auto-organizativo (Antonovsky fala de "equilíbrio homeostático") quando essa crença reforça o sentido interno de coerência que já se possuía, e do qual essa crença fazia parte. Nos entrevistados, porém, nos quais essa crença possuía, por exemplo, um valor puramente cultural e vago, dificilmente ela poderá ser utilizada como recurso de resistência, dado que não se incorpora no sentido interno de coerência que as pessoas foram construindo ao longo de suas vidas.

Assim, somente pessoas que foram desenvolvendo sentido interno de coerência não se desesperam durante muito tempo, mesmo face a adversidades sérias. Elas continuam a acreditar que, apesar de todo o sofrimento, a vida vale a pena continuar a ser vivida. Procuram, em circunstâncias difíceis, as pessoas com quem foram estabelecendo vínculos baseados nos afetos e confiança mútua; são conscientes dos seus direitos (e deveres) sociais face a circunstâncias graves e recorrem à comunidade para que deles possam usufruir. Nos nossos entrevistados, alguns referiram que buscaram as pessoas que em circunstâncias similares foram o seu suporte, por exemplo.

Quando, porém, o sentido interno de coerência se encontra pouco desenvolvido, dificilmente as pessoas recorrem aos recursos que a comunidade lhes disponibiliza. A vida com sofrimento torna-se incompreensível e sem significação, ou seja, sem sentido.

Se o SOC de cada um de nós está na base da nossa (in)capacidade em lidar com a adversidade, os recursos que vamos construindo ao longo da nossa história de vida contribuem, simultaneamente, para o reforço do nosso sentido interno de coerência, pois fazem-nos sentir confortados, protegidos, acompanhados nos momentos mais difíceis da nossa existência. Daí as observações de alguns dos entrevistados sobre como este tipo de experiência (a atual e outras similares, do passado) tinha sido fonte de aprendizagem, de valorização da vida e do relacionamento com os outros.

No que respeita ao SOC, consideramos também que seria de muito proveito pessoal, e comunitário, a estimulação do sentido interno de coerência das pessoas, quer em contexto de educação formal (como dos profissionais de saúde), quer no de educação não formal (na formação, por exemplo, de técnicos de serviço domiciliário, e do público em geral).

The decisive step forward, however, in formulating a theory was taken when I began to ask what do all these GRRs have in common, why do they seem to work. What united them, it seemed to me, was that they all fostered repeated life experiences which, to put it at its simplest, helped one to see the world as 'making sense', cognitively, instrumentally and emotionally. Or, to put it in information-systems theory terms, the stimuli bombarding one from the inner and outer environments were perceived as information rather than as noise. These strands of thought led to the emergence of the sense of coherence (SOC) construct, a generalized orientation toward the world which perceives it, on a continuum, as comprehensible, manageable and meaningful. The strength of one's SOC, I proposed, was a significant factor in facilitating the movement toward health. (Anonovsky, p. 15, 1996).

\section{Referências}

ANTONOVSKY, A. Health, stress and coping. New perspectives on mental and physical well-being. San Francisco; London: Jossey-Bass Publishers, 1985 .

ANTONOVSKY, A. Unraveling the mistery of health. Londres; San Francisco: Jossey-Bass Publishers, 1988.

ANTONOVSKY, A. The salutogenic model as a theory to guide health promotion. Health Promotion International, Oxford, v. 11, n. 1, p. 11-8, 1996. 
AROND-THOMAS, J. Disclosure and autonomic autopoiesis: A research and treatment model for twentyfirst century cancer survivorship. Advances in Mind-Body Medicine, New Jersey, v. 16, p. 13548, 2000 .

ERIKSSON, M.; e LINDSTRÖM, B. Validity of Antonovsky's sense of coherence scale: a systematic review. Journal of Epidemiology and Community Health, London, v. 59, p. 46o-6, 2005.

ERIKSSON, M.; LINDSTRÖM, B. A salutogenic interpretation of the Ottawa Charter. Health Promotion International, Oxford, v. 23, n. 2, p. 190-9, 2008.

JONAS, H. O princípio vida. São Paulo: Vozes, 2005 .

KUHN, T. The structure of scientific revolutions. Chicago: The University of Chicago Press, 1962.

WITTGENSTEIN, L. Investigações filosóficas. Lisboa: Fundação Gulbenkian, 1995. 